\title{
Luz, cámara... Educación del cuerpo y del carácter en el cine documental informativo de Max Glücksmann (1913-1915)
}

\section{Luzes, câmera... Educação no corpo e do caráter nos cinejornais de Max Glücksmann (1913-1915)}

\section{Light, camera... Education of the body and character in Max Glücksmann's newsreels (1913-1915)}

\author{
Eduardo Galak ${ }^{*}$
}

\begin{abstract}
RESUMEN
Se propone observar dos registros cinematográficos documentales producidos por Max Glücksmann en 1913 y 1915, los cuales muestran un grupo de cadetes del ejército entrenándose y otro de escolares realizando actividades físicas. El objetivo principal consiste en analizar los discursos estéticos y políticos que se desprenden de estos registros, utilizando recursos teóricos del campo de los estudios sobre cine, filosóficos e históricos de la educación del cuerpo y de las sensibilidades en Argentina. La intención es comprender las técnicas puestas en juego, cinematográficas y corporales, a partir de entender que desde los orígenes del cine y de la Educación Física existe una matriz común que articula imágenes simétricamente en movimiento que exhiben cuerpos simétricamente en movimiento.
\end{abstract}

Palabras-clave: Educación del cuerpo. Cine Documental Informativo. Técnicas. Simetría.

* Consejo Nacional de Investigaciones Científicas y Técnicas (CONICET). Universidad Nacional de La Plata. Buenos Aires, Argentina. E-mail: eduardogalak@gmail.com - https:/orcid. org/0000-0002-0684-121X 


\title{
RESUMO
}

Este trabalho tem como objetivo observar dois cinejornais documentários feitos por Max Glücksmann em 1913 e 1915, que mostram um grupo de cadetes do exército em treinamento e outro grupo de estudantes escolares fazendo atividade física. O objetivo principal é analisar os discursos estéticos e políticos que surgem a partir desses registros, usando literatura científica do campo teórico dos estudos do cinema, da filosofia e da história da educação do corpo e das sensibilidades na Argentina. Assim, a intenção é compreender as técnicas postas em jogo nas artes cinematográficas e corporais, para entender que, desde as origens do cinema e da Educação Física, existe uma matriz comum que articula imagens simetricamente em movimento, e que por sua vez também exibem corpos simetricamente em movimento.

Palavras-chave: Educação do corpo. Cine documentário. Técnicas. Simetria.

\begin{abstract}
The purpose is to observe two documentary newsreels made by Max Glücksmann in 1913 and 1915, which shows a group of army cadet training and another group of schoolchildren performing physical activities. The principal aim is to analyze the aesthetic and political discourses that emerge from these motion pictures, using theoretical resources from the philosophy, history, and cinematography field studies about corporal and sensibilities education in Argentina. The purpose is to understand the techniques put into play, cinematographic and bodily, understanding the general origins of cinema and Physical Education because of the articulation of symmetrically moving images that show symmetrically moving bodies.
\end{abstract}

Keywords: Body Education. Documentary Informative Cinema. Technics. Symmetry.

\section{Luz}

Los inicios de la cinematografía argentina pueden datarse con relativa precisión: sus orígenes se remontan al 18 de julio de 1896, fecha en la que se presentó por vez primera una proyección cinematográfica (primigenia también en Sudamérica), organizada por el empresario teatral Francisco Pastor y el periodista español Eustaquio Pellicer en el Teatro Odeón, en la cual se ven las breves escenas filmadas por los camarógrafos de los hermanos Auguste y Louis Lumière. Además de Pastor y Pellicer, se encontraba entre el escaso público el 
barón belga Henri Lepage, el joven austro-húngaro Max Glücksmann -nacido en 1875 con el nombre de Mordechai David-y el francés Eugenio Py. Justamente, apenas unos meses más tarde, en 1897, Eugenio Py dirige "La bandera argentina", la que se presume es la primera obra cinematográfica argentina, que consistió apenas en el registro documental de la filmación durante 3 minutos de la insignia patria que flamea en la Plaza de Mayo, en Buenos Aires. De hecho, las primeras décadas de la cinematografía argentina consistían en producciones fílmicas que se basaban principalmente en obras documentales que mostraban aspectos cotidianos de la vida cultural, política y militar nacional, especialmente eventos sociales de la aristocracia y burguesía urbanas. A fin de cuentas, eran realizaciones relativamente endogámicas, puesto que ellos mismos eran quienes podían darse "el lujo" de asistir a las funciones".

Esto es, el cine nace como documental, como gesto característicamente moderno de registro del presente para la posteridad. Inclusive, puede interpretarse un perfil cientificista en los inicios del registro fílmico, desde que uno de los orígenes de la cinematografía es la invención en 1882 del appareil de chronophotographie por parte de Étienne Jules Marey. El cronofotógrafo consiste en un artefacto científico creado para medir los cuerpos y los movimientos a partir de tomar fotografías a intervalos de tiempos regulares, permitiendo luego, mediante un mecanismo de proyección, generar un efecto óptico que produzca el pasaje de la imagen a la imagen en movimiento. A partir de haber adaptado un fusil para que "dispare" fotos de manera secuenciada, se inventa una tecnología que conjuga algunas cuestiones fundamentales para la ciencia moderna: regularidad, tiempo, control, registro, medición.

Ahora bien, además de haber inventado el cronofotógrafo, en su carácter de fisiólogo Marey es considerado uno de los padres de lo que se conoce como la "Educación Física científica", habiendo presidido la Ligue Nationale de l'Éducation Physique desde sus inicios en 1888. De hecho, muchas de las clásicas imágenes del cronofotógrafo de Marey fueron realizadas junto con uno de sus estudiantes colaboradores, Georges Demeny, considerado como el padre de la Éducation Physique Scientifique. Además de haber producido inventos científicos y divulgado sus ideas a través de publicaciones en revistas y libros, Demeny tuvo un rol significativo en la formación de profesionales en Educación Física, especialmente a través de su trabajo en la École Normale Militaire de Gymnastique de Joinville-le-Pont, una escuela militar de gimnasia creada en 1852 que trascendió fronteras (SOARES, 1994; SCHARAGRODSKY; GLEYSE, 2013).

$1 \mathrm{Al}$ respecto de la historia de la cinematografía argentina puede profundizarse en "Imágenes del mundo histórico. Identidades y representaciones en el noticiero y el documental en el cine mudo argentino" de Irene Marrone (2003) y en "Una historia del cine politico y social en Argentina. Formas, estilos y registros (1896-1969)" de Ana Laura Lusnich y Pablo Piedras (2009). 
Precisamente, las imágenes registradas por el cronofotógrafo de Marey y su asistente Demeny fueron de actividades desarrolladas en dos instituciones dedicadas a la cultura física de finales del siglo XIX en las que trabajaron: en la mencionada École Normale y en la Station Physiologique de Paris, una institución subvencionada por el Estado francés desde su fundación en 1882 con el propósito de estudiar los movimientos de la máquina humana y animal (POCIELLO, 1999; GLEYSE; BUI-XUÂN, 2002; ANDRIEU, 2003; SIMONET; VERAY, 2003).

Es justamente en 1882 el año en que Marey inventa junto con Demeny como asistente una cámara de placa fija cronomatográfica equipada con un obturador de tiempo: el appareil de chronophotographie. Esto es, en el marco de una institución creada para educar simultánea y homogéneamente los cuerpos por el Estado nacional, se da nacimiento a un invento científico que permite la fundación de la imagen en movimiento, de la image animée, la motion picture. Como puede verse, existe una matriz común entre el nacimiento del cine documental y de la Educación Física, cuya intersección se ubica en una racionalidad científica sobre los movimientos, pretendiendo medirlos, controlarlos, disciplinarlos, fortalecerlos, hacerlos higiénicos, resistentes y productivos. En otras palabras, tanto la Educación Física como el cine, tanto la educación del cuerpo sistematizada, institucionalizada y centralizada como la imagen-movimiento, nacen con la misma pretensión cientificista de asir los movimientos mediante técnicas que toman por objeto el cuerpo (GALAK, 2017).

Inclusive puede señalarse que la sociedad laboral conjunta entre ambos finaliza cuando Demeny pretende explotar económicamente estos inventos, mientras Marey pensaba que sólo debería tener fines científicos. A partir de allí Demeny se asocia con León Gaumont, dueño de la posteriormente famosa empresa que lleva su apellido, que luego se vincula con "Pathé" para formar el primer noticiero cinematográfico a nivel masivo, quizás la empresa de prensa cinematográfica más grande de la historia: "Pathé-Gaumont". Más allá de eso, esta asociación comercial entre la patente de Demeny y el capital de Gaumont permitió fabricar a mayor escala cámaras cinematográficas, y poder venderlas y distribuirlas internacionalmente.

Precisamente, con un "Cronofotógrafo Elgé" de 1897, de la compañía Gaumont-Demeny, se filma "La bandera argentina": la historia cuenta que Eugenio Py intenta comprarles ese año un cinematógrafo a los hermanos Lumière, pero, al fracasar las negociaciones, termina por adquirir un aparato de filmación de la compañía que había nacido tras el invento cientificista de medición de los cuerpos y de sus movimientos. Esta piona película Py la realiza en colaboración con "Enrique" Lepage, dueño de Casa Lepage y uno de los precursores del cine en Sudamérica, y junto con Max Glücksmann, uno de los privilegiados espectadores de aquella primera proyección fílmica en Argentina. 


\section{Cámara}

En la memoria colectiva argentina se asocian los noticieros cinematográficos con uno en particular, los "Sucesos Argentinos", creados por Antonio Ángel Díaz el 26 de agosto de 1938 en plena época de auge del cine sonoro. Su representatividad histórica puede explicarse por dos fenómenos. El primero refiere a su larga trayectoria en la producción de cine informativo, que superó las tres décadas, lo cual es imposible de ser comparado con las demás competidoras de la industria, que en su mayoría no superaban un decenio de existencia. El segundo, quizás más significativo, está signado por el hecho de que en diciembre de 1943 se reconfigura el mercado de la prensa cinematográfica: a través del Decreto número 18.405 (ARGENTINA, 1943) el Estado nacional se coloca a sí mismo como la principal entidad reguladora del rubro. Mediante el fomento de la realización y proyección de los noticieros, y gracias al aumento de pantalla por la obligación de que sean exhibidos en todas las salas del país antes de los filmes, el género de los noticieros cinematográficos tuvo su momento de esplendor, hasta ese momento inédito. El control estatal mediante este Decreto estaba explícitamente centrado en reglamentar algunas cuestiones técnicas, como que su duración no sea inferior a los ocho minutos o la distribución para que llegue a las distintas ciudades. Si bien no existía una regulación gubernamental de los contenidos -sí existió la promoción u obstaculización mediante la asignación de subsidios, y en algunos casos censura más o menos explícita-, cierto es que la bajada de línea editorial de los noticieros cinematográficos en Argentina estuvo en correspondencia con el clima político de época ${ }^{2}$. En ese contexto de pleno auge, los "Sucesos Argentinos" se vieron beneficiados por el Decreto con el 70\% de las pantallas de los cinemas nacionales (GALAK, 2021).

Ahora bien, incluso cuando su famoso autoproclamado lema de "Primer semanario cinematográfico latinoamericano" sitúa a los "Sucesos" como pioneros del género, cierto es que el carácter de precursor del cine informativo argentino puede ser identificado en las llamadas "Actualidades" o "Actualidades argentinas". En una iniciativa relativamente particular y sin pretensiones estrictamente comerciales, Mordechai David "Max" Glücksmann fundó una productora con el objetivo de registrar acontecimientos sociales y proyectarlos 
en salas de cinemas ${ }^{3}$. En este sentido, la productora "Cinematografía Max Glücksmann" resultó una de las primeras en importar, filmar y proyectar cintas cinematográficas en Argentina, no sólo en su capital Buenos Aires, sino en el interior e inclusive en Uruguay, Paraguay y Chile (DI NÚBILA, 1998). Inclusive entre las "Actualidades" de Glücksmann y los "Sucesos Argentinos" se encuentra el micro de noticias "Film Revista Valle", producido por un pionero de la cinematografía argentina como fue el italiano Federico Valle, que entre 1920 y 1930 realizó un semanario proyectado en los cines que apareció puntillosamente durante diez años seguidos los jueves a las 17:00hs, llegando a las 657 ediciones que lamentablemente en su enorme mayoría se perdieron (DI NÚBILA, 1998).

Dentro de este contexto, cabe señalar que se calcula que el $90 \%$ de la producción fílmica silente argentina de entre finales del siglo XIX y la primera mitad del XX se encuentra perdida por diversos motivos (CUARTEROLO, 2013), lo cual claramente complica cualquier indagación sobre registros audiovisuales históricos ${ }^{4}$. Más aún, su conservación no está cabalmente garantizada: si bien existe en la Argentina una reglamentación de cuidado patrimonial, que lega las responsabilidades en el Archivo General de la Nación - organismo dependiente del Ministerio del Interior -, ésta no incluye directamente al cine documental informativo - especialmente el tipo noticieros cinematográficos - ya que son interpretadas como un género intermedio entre lo ficcional y lo documental propiamente dicho ${ }^{5}$.

En este escrito se analizan precisamente dos documentos fílmicos que se encuentran en el Archivo General de la Nación, y registran dos sucesos de la década de 1910 que ponen a las ejercitaciones físicas como principal actividad. En este sentido, resulta preciso indicar que estas secuencias de fotogramas son relativamente rarezas por la época en que son filmadas, existiendo escasos registros de este tipo en todo el mundo - lo cual supone la originalidad y relevancia de esta investigación -, a diferencia de lo que ocurre especialmente desde el segundo cuarto del siglo XX cuando el rodaje de prácticas corporales se torna común dentro del cine informativo-documental, y también del ficcional (MELO, 2004). Esa fascinación de la cámara por el

3 Además de realizador cinematográfico, cabe destacar que fue dueño del legendario Cine Splendid, mecenas - aportando a la construcción de la importante sinagoga de la calle Libertad en la ciudad de Buenos Aires - y productor discográfico - siendo, por ejemplo, el primero en contratar a Carlos Gardel.

$4 \mathrm{Al}$ respecto se recomienda profundizar con "La imagen ausente: el cine mudo argentino en publicaciones gráficas. Catálogo. El cine de ficción (1914-1923)" de Lucio Mafud (2016).

5 A ello puede sumarse que no existe en la Argentina un acervo documental audiovisual sobre la Educación Física, cuestión que se analiza en "Las (im)posibilidades de una historia audiovisual de la Educación Física argentina” (GALAK; PEREYRA, 2020). 
registro de prácticas corporales se explica en parte por el hecho de que, si el cine es imagen en movimiento, entonces las actividades físicas entrañan un buen recurso para ser cinematografiado.

Antes de pasar a un detalle analítico de cada uno de estos micros fílmicos, es importante señalar que el cine silente en blanco y negro presenta un desafío metodológico, distinto al que se acostumbra cuando se piensa en términos de estética en el género audiovisual, a la luz de los adelantos tecnológicos actuales. De allí que para observarlos se utilicen tanto estudios historiográficos sobre el cine documental argentino como reflexiones filosóficas al respecto. Entre los primeros se destacan los trabajos de Irene Marrone (2003), Clara Kriger (2007, 2009), Ana Laura Lusnich y Pablo Piedras (2009) y Andrea Cuarterolo (2009, 2013, 2015), en tanto que en el segundo conjunto se ubican los sentidos estéticos de Gilles Deleuze (2009), la conceptualización de Marcel Mauss (1996) sobre las "técnicas corporales" y los conceptos de "reproductibilidad técnica" de Walter Benjamin (2012) y de "estética de la política" y "política de la estética" de Jacques Rancière (2012). A su vez, como una suerte de posicionamiento teórico intermedio, se reflexiona a partir de la "teoría de los intervalos" del cineasta ruso Dziga Vértov (1974), precursor del género con sus Kino-pravda.

\section{Acción}

Cuando en 1913 y 1915 Max Glücksmann filmó un concurso infantil de ejercicios físicos y cadetes del ejército nacional argentino haciendo actividades gimnásticas estaba dando inicio a un modo particular de registrar y mostrar la realización de prácticas corporales. En efecto, estos dos micros fílmicos informativo-documentales producidos por uno de los precursores de la cinematografía sudamericana permiten analizar, por un lado, una significación estética de la educación de los cuerpos, en el cual se manifiestan formas simétricas, ordenadas (en su doble acepción, metódicas y comandadas), repetitivas, coreográficas, todos haciendo todo, por turnos, y, por el otro, un sentido de lo que hay que mostrar articulado con un sentido de lo que hay que hacer. Ambos son en blanco y negro, silentes, y con tomas de planos generales cortos con una secuencia de imágenes cronológica según la actividad registrada.

El primero de los registros fílmicos es del 23 de febrero de 1913, con una duración de 6 minutos y 40 segundos, muestra un "Concurso de ejercicios fisicos organizados por el Club Mar del Plata bajo la dirección del Profesor Sr. Juan Rosi", tal como expone el intertítulo inicial que está firmado por "“Casa Lepage' 
de Max Glücksmann". Si bien en el documento fílmico refiere a Juan Rosi, se interpreta que se trata de Juan Rossi, quien fuera en 1901 alumno ingresante a la Escuela Militar de Gimnasia y Esgrima (segundo curso), posteriormente egresado y destinado en 1903 junto a Aniceto Rodríguez al Batallón 5 de infantería, y quien estuviera un periodo en el Círculo Militar hasta 1909. Es importante señalar que es en ese mismo año, 1909, en el cual se produce la autorización de los egresados de la Escuela de Gimnasia y Esgrima del ejército argentino a dictar clases en los establecimientos escolares nacionales (GALAK, 2019), lo cual explica por qué el docente de las imágenes de 1913 proviene de una formación militar.

Las imágenes muestran que, frente a la rambla principal de la ciudad balnearia, un grupo de niños varones vestidos todos iguales, con pantalones oscuros, camisa blanca y corbata negra, se reúnen para realizar saltos de altura sobre una soga, disputas lúdicas agonísticas sobre una viga para derribar al oponente o el tradicional juego de comer una manzana colgada de una soga sin la ayuda de las manos, para finalizar esta secuencia en la playa con ejercitaciones individuales con clavas. Todo ello bajo la atenta mirada de fondo de un público parado en unas tarimas colocadas sobre la arena. Luego aparecen los jóvenes en lo que parecería ser una calle, haciendo ejercicios calisténicos, en filas e hileras de frente al profesor del cual copian la actividad, con movimientos únicamente de brazos tomando un aparato gimnástico. Los fotogramas continúan mostrando rotaciones de cadera, de brazos, haciendo círculos con ambos hombros para el mismo lado, asimétricamente, seguidas de saltos individuales sobre una soga sosteniendo un implemento, ejecutados en dúos. Las imágenes se suceden con unos juegos de persecución entre todos, pero por turnos, siendo apenas dos -de un grupo de una veintena de niños- los que participan mientras el resto los observa, y unas carreras colectivas hacia donde está la cámara. Cierra el micro fílmico una demostración de esgrima de apenas unos segundos de duración entre el profesor y un alumno. 
IMAGEN 1 - INTERTÍTULO INICIAL DEL "CONCURSO DE EJERCICIOS FÍSICOS" ESCOLARES

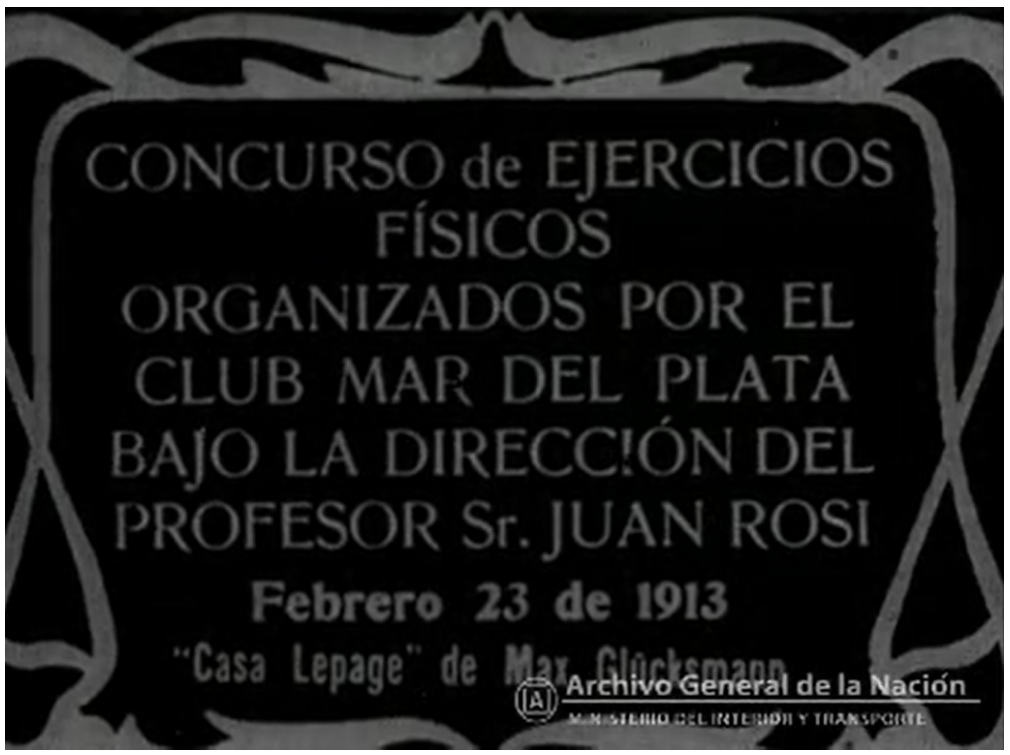

FUENTE: Fotograma de "Concurso de ejercicios físicos” escolares - Max Glücksmann (1913).

En tanto que el segundo micro fílmico es del 19 de julio de 1915, tiene un tiempo de 2 minutos y 20 segundos en los que exhibe "El $45^{\circ}$ aniversario del Colegio Militar", según consta en el intertítulo inicial de Glücksmann Journal. ${ }^{6}$ Comienza por mostrar la llegada del Estado Mayor del ejército, seguido por un desfile de cadetes con una banda militar de música y armas en mano, marchando en filas e hileras uniformemente. Entre quienes presenciaban el acontecimiento se encontraba Eugenio Pini, esgrimista italiano que resultó una figura clave en la institucionalización de la Educación Física argentina, ya que fue el primer director de la Escuela de Gimnasia y Esgrima, organismo estatal dependiente del ejército (GALAK, 2019; LEVORATTI; SCHARAGRODSKY, 2018), inclusive inspirándose en la mencionada École Normale Militaire de Gymnastique de Joinville-le-Pont. Luego de una placa en la que se lee "Ejercicios de gimnasia" continúan una serie de ejercitaciones de cadetes en un patio al aire libre, en cuyo fondo se observa, como espectadores, hombres vestidos con uniformes

6 Puede suponerse que esta referencia a los noticieros de Glücksmann como "Journal" estaba destinada a su exhibición también por fuera de Latinoamérica. 
castrenses. Uno a uno pasan los prebostes por un caballete, haciendo un salto y caída con todo el cuerpo rígido, para luego ir sumando altura en el instrumento gímnico. La secuencia de imágenes sigue con una muestra de ejercicios individuales en paralelas, mientras que detrás del plano principal otros cadetes trepan la soga y realizan otras actividades.

\section{IMAGEN 2 - CADETES HACIENDO EJERCICIOS FÍSICOS}

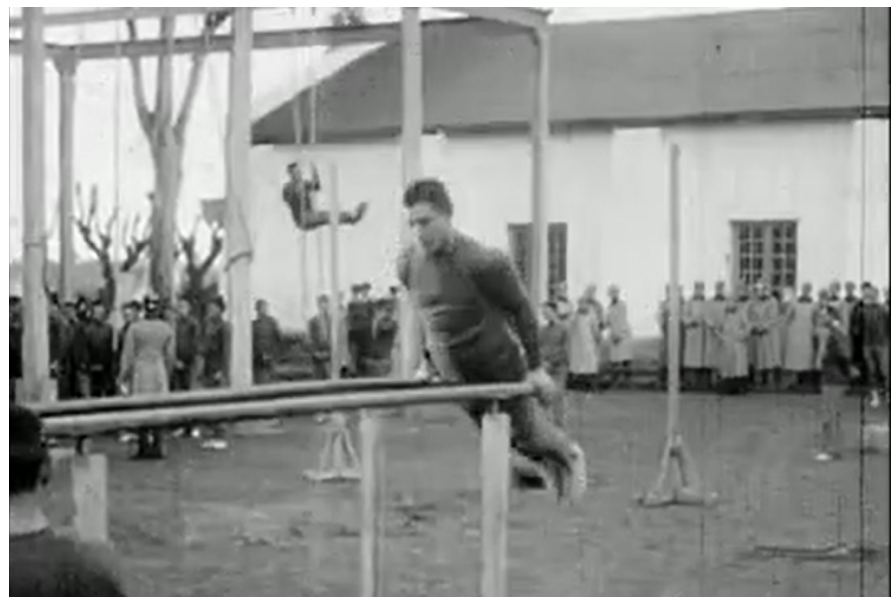

FUENTE: Fotograma de "El 45 aniversario del Colegio Militar" - Max Glücksmann (1915).

La filmación de entrenamientos calisténicos a través de las "Actualidades Argentinas" de Glücksmann muestra de manera casi igual actividades físicas realizadas entre niños escolares y jóvenes militares, ejercitándose armoniosamente en filas e hileras bajo la orden de un profesor de Educación Física, de espaldas a la cámara pero frente a quienes cumplen con sus directivas. Estas imágenes en movimiento reflejan una analogía entre técnicas corporales y técnicas cinematográficas: la secuencia de fotogramas encuadra una racionalidad simétrica que homogeneiza los cuerpos y universaliza los sentidos estéticos que se proyectan. Precisamente allí radica el horizonte de análisis: comprender cómo se usa(ro)n paralelamente las imágenes y los movimientos como técnicas políticas y estéticas para, retomando la clásica tesis de Walter Benjamin (2012), hacer de la reproductibilidad mecánica de la cinematografía un dispositivo de la reproducción estético-política.

Siguiendo las categorías propuestas por Georges Vigarello (2005) acerca de los métodos de movimiento correctos que se constituyen en la modernidad, las imágenes expresan un sentido de actividad física que prioriza la "mostración" 
y la "frontalidad" de los gestos, además de transmitirse mediante recursos audiovisuales una "geometrización de los cuerpos", la cual educa la sensibilidad por un nuevo valor social, como es la idea de simetría. Esto es, en boga por aquellos años, el ideario de "orden" se vuelve junto con su hermano político "progreso" el paradigma epistémico que gobierna las razones de por qué realizar institucional y centralizadamente prácticas corporales: una simetría del movimiento, de los cuerpos, de las subjetividades. Estas categorías resultan una suerte de paradigma de las técnicas corporales, que a las luces y sombras de la captura de la cámara y las técnicas cinematográficas de la época se constituyen en un dispositivo para la (re)producción política y estética (RANCIÈRE, 2014). Ello supone un telón de fondo sobre el cual se percibe un modo particular de educar al espectador (RANCIÈRE, 2010), enseñando simultáneamente cómo hacer correctamente los ejercicios mediante la mostración, al mismo tiempo que se instruía cómo mirar los movimientos. De esta manera, se educa (con) la mirada para una formación de las subjetividades (DUSSEL; GUTIÉRREZ, 2006; GALAK, 2017).

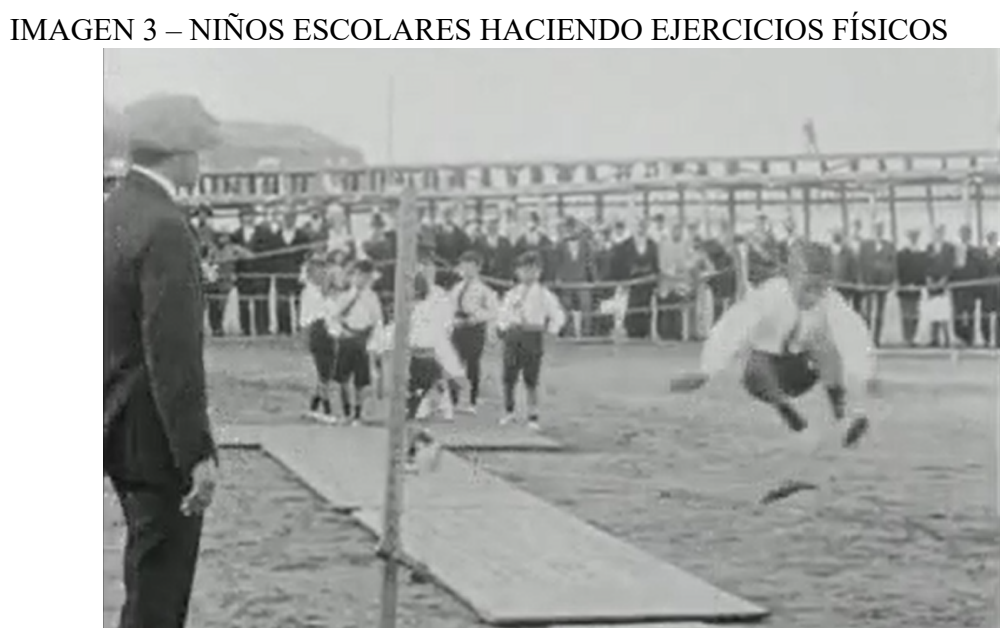

FUENTE: Fotograma del “Concurso de ejercicios físicos” escolares - Max Glücksmann (1913).

Es posible observar en las imágenes una puesta en escena de lo que Marcel Mauss (1996) explicita como "técnicas corporales", no sólo en las acciones desarrolladas por los alumnos escolares o prebostes militares, sino también en el rol del profesor de Educación Física, ubicado en un plano secundario en las filmaciones, pero frontal en las dos demostraciones gimnásticas, procurando 
cierta automatización del movimiento, cierta incorporación de las técnicas. Esto es, es posible pensar que la tecnología de la imagen en movimiento funcionaba como proyección de dos técnicas que funcionaron articuladamente como engranajes: las técnicas corporales y las técnicas cinematográficas permitieron reproducir de modo análogo imágenes en movimiento de cuerpos en movimiento. Ello puede verse de manera elocuente en la locación de estas actividades: ambas fueron desarrolladas al aire libre, y puede interpretarse que ello se debe tanto a una cuestión de luminosidad para el registro fílmico como por una pretensión de favorecer los desplazamientos en un espacio más amplio o de poder mostrar las ejercitaciones físicas a los espectadores - sean los demás participantes, la plana mayor del ejército o el público en general.

Además, no son menores dos contigüidades entre los micros fílmicos. La primera es que existe una matriz común en ambos registros y es el hecho que son desarrolladas siguiendo los criterios del posicionamiento militarista de la Educación Física, caracterizado por su estricta masculinidad, por el conservadurismo en la formación del carácter, por su gimnasia artificial con implementos, por la rigidez en sus movimientos y por la fuerza y la resistencia como capacidades motoras más relevantes. Ello es visible claramente en el documento audiovisual de 1915 con motivo del $45^{\circ}$ aniversario del Colegio Militar, a la vez que en el de 1913 es efecto de que el profesor de Educación Física escolar de las filmaciones marplatenses es Juan Rossi, uno de los egresados de la extinta Escuela Militar de Gimnasia y Esgrima del ejército en 1901 - destinado en 1903 al Batallón 5 de Infantería y con actuación en el Círculo Militar. La segunda, íntimamente relacionado con la primera, es que los micros fílmicos de Glücksmann exhiben un tipo particular de ejercitación, que son aquellas gimnasias calisténicas, con filas e hileras de practicantes simétricamente dispuestos, ejecutando simultáneamente. Como técnica corporal característica de la época, los ejercicios de calistenia permiten que los alumnos - militares o escolares - desarrollen al mismo tiempo la actividad física, estableciendo una normalidad del movimiento a ser ejecutado, en un ritmo específico, que todos deben copiar siguiendo el comando directo del docente a cargo. Como sinécdoque de la cultura física de la época, esta es una manera paradigmática de establecer científicamente orden, racionalidad, tempo, regularidad y secuencia de los movimientos, disponiendo los cuerpos para su medición y las subjetividades para su control. Cuestiones que tanto la Educación Física estatalmente sistematizada como la cinematografía documental se valieron para su desarrollo. 


\section{IMAGEN 4 - NIÑOS ESCOLARES HACIENDO EJERCICIOS FÍSICOS}

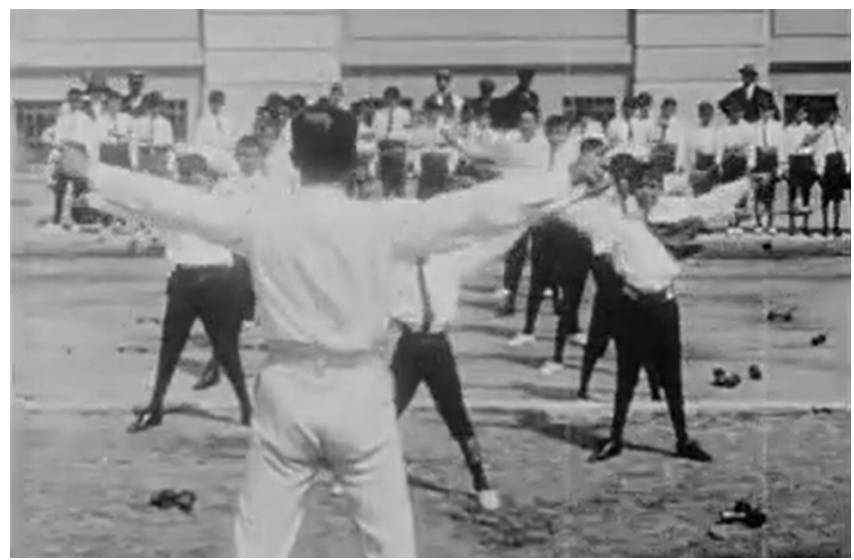

FUENTE: Fotograma del “Concurso de ejercicios físicos” escolares - Max Glücksmann (1913).

\section{¡Corte!}

Las imágenes en movimiento analizadas muestran una prolongación de la matriz común entre el nacimiento del cine documental y los orígenes de la cultura física, especialmente visibles en la racionalidad científica que pone el énfasis sobre las técnicas de movimientos. En otras palabras, las imágenesmovimientos de cuerpos en movimiento registrada por Glücksmann reflejan la racionalidad técnica científica del cine y de la Educación Física que se haya en sus respectivos orígenes desde la invención de aparatología de medición de los cuerpos por parte de Étienne Jules Marey y Georges Demeny.

A trasluz de estas imágenes puede observarse que las filmaciones registran ejercicios institucionalizados, de una clase social particular posible de ser categorizada como burguesa, el exhibicionismo de lo público, al aire libre con espectadores pasivos, cinematografiadas con una cámara estática colocada a la altura del observador, con planos generales cortos que incluyen apenas la actividad y sus principales participantes. Los fotogramas de estas "Actualidades" exponen como concepto visual la simetría, de cuerpos homogeneizados, de sentidos estéticos universalizados, de discursos políticos masivamente proyectados.

En cuanto a los registros fílmicos a la luz de los debates historiográficos del campo de la Educación Física argentina, puede interpretarse cierta contigüidad entre ambos micros fílmicos al tratarse de actividades desarrolladas por 
profesionales formados por la Escuela de Gimnasia y Esgrima del Ejército. En ese sentido, dos cuestiones sobresalen de estas imágenes: la priorización de la fuerza como capacidad motora y la simetría de los ejercicios. Puede interpretarse que ello redunda en la pretensión de formar cadetes militares o niños escolares que sean hombres viriles, como sinónimos de un físico y carácter fuertes, y dóciles, como analogía de sumisos frente a un colectivo.

A través de las imágenes filmadas por este pionero de la cinematografía argentina, registradas para su experimental cine informativo, pueden verse sentidos institucionalizados de cómo moverse, al mismo tiempo que se refleja la dimensión pragmática de tales actividades gimnásticas para la transmisión de sentidos definidos (heteronormativos de vigorosidad, de fortalecimientos de los músculos para el perfeccionamiento de la raza, nacionalistas conservadores, etcétera) para la formación del carácter. Si bien la importancia de estos fotogramas, lo interesante es que no reflejan el sentido oficial de cultura física en la Argentina, puesto que desde 1905 hasta fines de la década de 1930 el método legalmente establecido era el Sistema Argentino de Educación Física, propuesto por el médico Enrique Romero Brest, contrario a la formación militarista de prácticas corporales, especialmente en lo que respecta a la educación escolar. Es decir, las imágenes más antiguas de la Educación Física argentina no muestran el sistema estatal, sino que exhiben las técnicas que eran enseñadas por parte de miembros del ejército, para prebostes y niños escolares. Puede suponerse que ello se debe a que estas instituciones tienen históricas relaciones con los círculos conservadores de élite citadina, por lo que se filmaron este tipo de actividades para que sean proyectadas dentro del mismo círculo. En otras palabras, no es tanto el registro de la realidad, sino la proyección de una realidad deseada.

Especialmente se destaca la simetría del movimiento como técnica, a la vez corporal y cinematográfica. Ello puede verse en dos dimensiones articuladas: por un lado, la del recurso teórico que permite la práctica cinematográfica, como explica Dziga Vértov en su "teoría de los intervalos" (1974) y refrendan - no sin tensiones - Gilles Deleuze (2009) y Jacques Rancière (2012) cuando afirman que lo que importa en el cine no es la imagen ni su movimiento aislados, sino sus distancias armónicas entre sí; en tanto que, por el otro, puede pensarse en la de los cuerpos filmados, producto del método gimnástico empleado, que reproduce como ideario la simetría como valor moral (VIGARELLO, 2005; GALAK, 2017). En definitiva, puede interpretarse la pretensión de formar el carácter en cada cadete o alumno, de uniformarlos simétricamente, exhibiendo a través de los fotogramas la preponderancia de las técnicas por sobre los movimientos, sean cinematográficas o corporales. 


\section{REFERENCIAS}

ANDRIEU, Gilbert. L'École de Joinville contrainte au changement (1872-1914). Cahiers de l'INSEP, hors-série, [s.l.], p. 31-45, 2003.

ARGENTINA. Decreto $N^{\circ} 18.405,31$ de diciembre 1943. Fomento de la producción de noticiarios nacionales. Buenos Aires: Registro Nacional, 1943. Disponible en: http:// www.ricila.com/wp-content/uploads/Argentina.-Derecho-Cinematogr\%C3\%A1fico.pdf. Acceso en: 13 dez. 2020.

BENJAMIN, Walter. La obra de arte en la era de su reproductibilidad técnica y otros textos. Buenos Aires: Godot, 2012.

CUARTEROLO, Andrea. Los antecedentes del cine político y social en la Argentina (1896-1933). En: LUSNICH, Ana Laura; PIEDRAS, Pablo. Una historia del cine político y social en Argentina. Formas, estilos y registros (1896-1969). Buenos Aires: Nueva Librería, 2009. p. 145-172.

CUARTEROLO, Andrea. Introducción: Investigar sobre cine silente 1 en Latinoamérica. Imagofagia, Ciudad Autónoma de Buenos Aires, n. 8, p. 1-14, 2013.

CUARTEROLO, Andrea. El cine científico en la Argentina de principios del siglo 20: entre la educación y el espectáculo. História da Educação, Porto Alegre, v. 19, n. 47, p. 51-73, 2015.

DELEUZE, Gilles. Cine I: Bergson y las imágenes. Buenos Aires: Cactus, 2009.

DI NÚBILA, Domingo. La época de oro. Historia del cine argentino. Buenos Aires: Ediciones del Jilguero, 1998.

DUSSEL, Inés; GUTIÉRREZ, Daniela. Educar la mirada. Políticas y pedagogías de la imagen. Buenos Aires: OSDE, 2006.

GALAK, Eduardo. Educar (con) la mirada. Discursos políticos y sentidos estéticos sobre la cultura física en noticieros cinematográficos. En: OSSENBACH SAUTER, Gabriela (comp.). Gregorio Weinberg: escritos en su honor. Buenos Aires: CLACSO, 2017. p. 55-74.

GALAK, Eduardo. La institucionalización del oficio de pedagogizar los cuerpos: el nacimiento de la formación profesional en Educación Física en Argentina (1897-1912). História da Educação, Porto Alegre, v. 23, e79633, 2019.

GALAK, Eduardo. El día de la Educación Física en el noticiero cinematográfico "Sucesos Argentinos" durante el peronismo (1946-1955). Historia Social y de la Educación, Barcelona, v. 10, n 1, p. 1-21, 2020.

GALAK, Eduardo; PEREYRA, Martín. Las (im)posibilidades de una historia audiovisual de la Educación Física argentina. Ágora para la Educación Física y el Deporte, Valladolid, España, v. 22, p. 106-123, 2020. 
GLEYSE, Jacques; BUI-XUÂN, Gilles. L'émergence de l'éducation physique. Georges Demenij (1850-1917) et Georges Hébert (1875-1957). Paris: Hatier, 2002.

KRIGER, Clara. El noticiero Sucesos Argentinos. Historiapolitica.com, Buenos Aires, 2007. Disponible en: http://historiapolitica.com/datos/biblioteca/kriger.pdf. Acceso en: 15 dez. 2020.

KRIGER, Clara. Cine y peronismo: el estado en escena. Buenos Aires: Siglo XXI, 2009.

LEVORATTI, Alejo; SCHARAGRODSKY, Pablo. La formación de los educadores físicos civiles y militares en los primeros años del siglo XX en Argentina. Educación Física y Deporte, Medellín, v. 37, n. 1, p. 9-27, 2018.

LUSNICH, Ana Laura; PIEDRAS, Pablo. Una historia del cine politico y social en Argentina. Formas, estilos y registros (1896-1969). Buenos Aires: Nueva Librería, 2009. v. 1.

MAFUD, Lucio. La imagen ausente. El cine mudo argentino en publicaciones gráficas. Catálogo. El cine de ficción (1914-1923). Buenos Aires: Ediciones Biblioteca Nacional, Teseo, 2016.

MARRONE, Irene. Imágenes del mundo histórico. Identidades y representaciones en el noticiero y el documental en el cine mudo argentino. Buenos Aires: Biblos, 2003.

MAUSS, Marcel. Las técnicas del cuerpo. En: CRARY, Jonathan; KWINTER, Sanford (ed.). Incorporaciones. Madrid: Cátedra, 1996. p. 385-407.

MELO, Victor. Esporte, imagem, cinema: diálogos. Rio de Janeiro: Programa Avançado de Cultura Contemporânea, 2004.

POCIELLO, Christian. La Science en mouvements: Étienne Marey et Georges Demenÿ (1870-1920). Paris: PUF, 1999.

RANCIÈRE, Jacques. El espectador emancipado. Buenos Aires: Manantial, 2010.

RANCIÈRE, Jacques. Las distancias del cine. Buenos Aires: Manantial, 2012.

RANCIÈRE, Jacques. El reparto de lo sensible: estética y política. Buenos Aires: Prometeo, 2014.

SCHARAGRODSKY, Pablo; GLEYSE, Jacques. El Dr. Enrique Romero Brest, las visitas a instituciones europeas de formación y el Congreso de Educación Física realizado en 1913 como indicadores de la globalización y la nacionalización de la «cultura física». Staps, [s.l.], n. 100, p. 89-107, 2013.

SIMONET, Pierre; VERAY, Laurent. Introduction. L'Empreinte de Joinville, 150 ans de sport. Les Cahiers de l>INSEP, hors-série, [s.l.], p. 9-11, 2003.

SOARES, Carmen Lucia. Educação Física: raízes européias e Brasil. Campinas: Autores Associados, 1994. 
GALAK, E. Luz, cámara ... Educación del cuerpo y del carácter en el cine documental informativo...

VÉRTOV, Dziga. El cine ojo. Madrid: Fundamentos, 1974.

VIGARELLO, Georges. Ejercitarse, jugar. En: VIGARELLO, Georges; CORBIN, Alain; COURTINE, Jean-Jacques. Historia del cuerpo. Madrid: Taurus, 2005. p. 229-292.

Texto recibido en 26/09/2020.

Texto aprobado en 18/12/2020. 